\title{
Clinical utility of apixaban in the prevention and treatment of venous thromboembolism: current evidence
}

This article was published in the following Dove Press journal:

Drug Design, Development and Therapy

5 November 2014

Number of times this article has been viewed

\author{
Ali Zalpour' \\ Thein Hlaing $\mathrm{Oo}^{2}$ \\ 'Division of Pharmacy - Clinical \\ Programs, ${ }^{2}$ Section of Thrombosis and \\ Benign Hematology, The University of \\ Texas MD Anderson Cancer Center, \\ Houston, TX, USA
}

\begin{abstract}
Anticoagulation with heparin and vitamin $\mathrm{K}$ antagonist has been the mainstay of prevention and treatment of venous thromboembolism (VTE) for many years. In recent years, novel oral anticoagulants such as dabigatran etexilate (a direct thrombin inhibitor) and rivaroxaban, apixaban, and edoxaban (a direct factor Xa inhibitor) have emerged for the prevention and treatment of VTE. Novel oral anticoagulants have been shown to be noninferior to vitamin K antagonist or heparin in the prevention and treatment of VTE. This review specifically examines the role of apixaban in the prevention and treatment of VTE based on the available literature. The management of apixaban in the perioperative setting is also explored because some patients on apixaban may require surgical intervention. Finally, we discuss the management of apixaban-induced major bleeding complications, the relevance of drug-drug interactions, and patient education.
\end{abstract}

Keywords: new oral anticoagulants, apixaban, venous thromboembolism, thromboprophylaxis

\section{Introduction}

Low-molecular-weight heparins (LMWHs) and vitamin K antagonist (VKA) have been considered the first-line option for the prevention and treatment of venous thromboembolism (VTE) for several years. ${ }^{1}$ Fondaparinux, an injectable form of factor Xa (FXa) inhibitors (FXa-I) was recently introduced, which paved the way for the introduction of novel oral anticoagulants (NOACs). This exploration was undertaken because VKA offered unpredictable pharmacodynamic (PD) and pharmacokinetic (PK) properties and numerous drug-drug and drug-food interactions that necessitate periodic international normalized ratio (INR) level monitoring. ${ }^{2}$ LMWHs and fondaparinux offer a more predictable PK/PD profile, but patients are subjected to injections that can be burdensome. The introduction of NOACs was an attempt to improve the $\mathrm{PD} / \mathrm{PK}$ properties of anticoagulants with efficacy similar to that of previous-generation anticoagulants without the frequent monitoring requirements. Dabigatran, an oral direct thrombin inhibitor (DTI), and rivaroxaban, an oral FXa-I, are available on the market for VTE prevention following hip and knee surgery, and for the treatment of VTE. Apixaban, another FXa-I, is also currently approved for the prevention of VTE following major orthopedic surgery. Numerous trials have shown noninferiority of NOACs to standard-of-care anticoagulants designed to meet this need. ${ }^{1}$
Correspondence: Thein Hlaing Oo Section of Thrombosis and Benign Hematology, The University of Texas MD Anderson Cancer Center, 1515 Holcombe Blvd, Unit 1464, Houston, TX 77030, USA

$\mathrm{Tel}+\mathrm{I} 7135633460$

Fax +I 7I35634443

Email thoo@mdanderson.org 


\section{Physiology of hemostasis and pharmacology of apixaban \\ Physiology of hemostasis}

The formation of a clot at a site of injury involves four phases: exposure of tissue factor from the endothelium that leads to the initiation phase or binding of platelets to collagen; propagation or recruitment of platelets to the growing clot; amplification of the coagulation cascade; and stabilization or platelet-platelet interaction with fibrin deposition. ${ }^{3}$ Tissue factor released from the endothelium during the initiation phase induces the activation of factors VII and X, and the conversion of prothrombin to thrombin (IIa). In the amplification and propagation phases, thrombin activates platelets and factors V, VIII, IX, X, and XI. The formation of the prothrombinase complex amplifies IIa, thereby activating more platelets and the induction of hemostasis (Figures 1 and 2). ${ }^{4,5}$ Historically, VKA inhibit factors II, VII, IX, and X. Unfractionated heparin (UFH) and LMWHs inhibit factors II and Xa. ${ }^{6,7}$ In recent years, more targeted anticoagulants that inhibit FXa were introduced. Recently approved oral FXa-I, such as rivaroxaban and apixaban, inhibit free and clot-bound FXa in the prothrombinase complex. ${ }^{8}$

\section{Pharmacodynamics and pharmacokinetics of apixaban}

Apixaban inhibits FXa by binding to its active site. Apixaban inhibits free as well as clot-bound FXa (part of the prothrombinase complex). ${ }^{9}$ Apixaban (after the administration of a $20 \mathrm{mg}$ dose) reaches a maximum concentration of 460 $\mathrm{ng} / \mathrm{mL}$ with an area under the curve of $4,100 \mathrm{ng} \cdot$ hour $/ \mathrm{mL} .{ }^{10}$
Table 1 lists the PD and PK properties of apixaban. Protein binding of apixaban is about $87 \%$ (nondialyzable) with gastrointestinal absorption of $50 \%$. Apixaban takes a time of 3-4 hours to reach a maximum concentration with a volume of distribution of $21 \mathrm{~L} \cdot{ }^{11-13}$ Apixaban is metabolized by the hepatic CYP3A4/5 system and is a substrate for P-glycoprotein (P-gp) and breast cancer resistance protein. Apixaban is excreted $23 \%$ renally and $75 \%$ via the biliary route. The half-life of apixaban increases with various degrees of renal function, and is between 11 hours and 18 hours. ${ }^{11-13}$

\section{Apixaban VTE clinical trials Primary thromboprophylaxis in orthopedic surgery}

Without thromboprophylaxis, the incidence of hospitalacquired deep vein thrombosis (DVT) based on diagnostic screening is $40 \%-60 \%$ among patients who have undergone major orthopedic surgery such as total hip replacement (THR) and total knee replacement (TKR). ${ }^{14}$ Despite chemical and mechanical prophylaxis, the prevalence of VTE after THR, TKR, or bilateral TKR had been reported at $8.9 \%, 25.6 \%$, and $36.9 \%$, respectively. The prevalence of symptomatic nonfatal in-hospital pulmonary embolism (PE) was $1.9 \%$, while the prevalence of fatal in-hospital PE was $0.05 \% .{ }^{15}$ The American College of Chest Physicians (ACCP) recommends the use of LMWH, fondaparinux, low-dose UFH, adjusted-dose VKA, aspirin (all grade 1B), or an intermittent pneumatic compression device (grade 1C) for 10-14 days for prophylaxis for patients undergoing THR or TKR. ${ }^{16}$ Based on the following apixaban trial results, the United States Food and

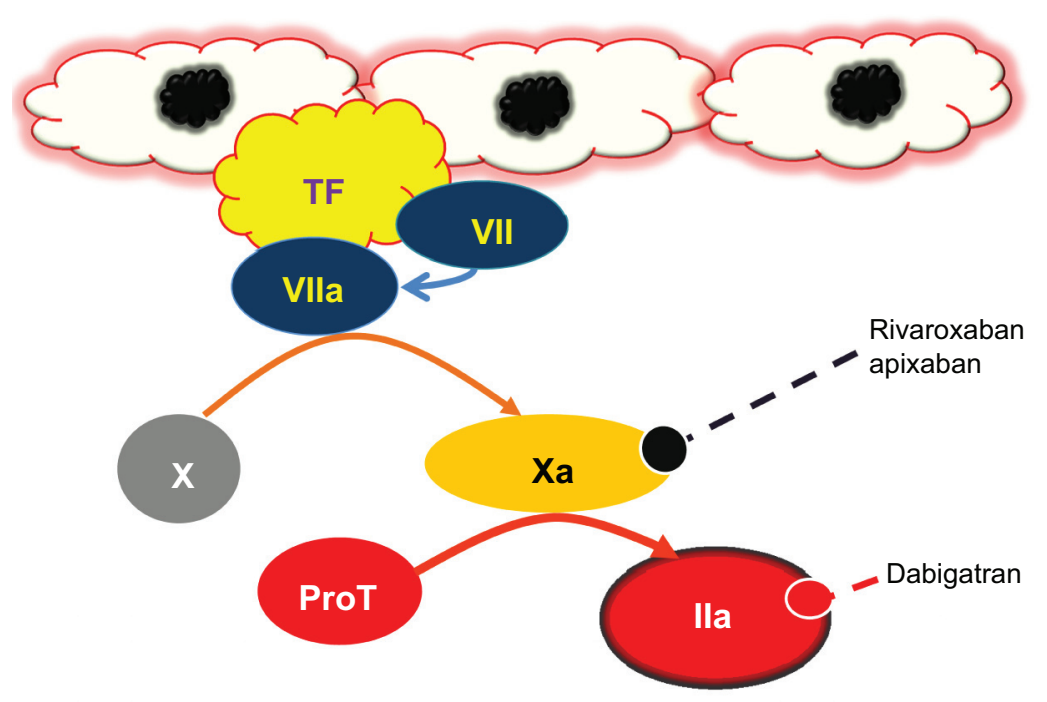

Figure I Initiation cascade.

Abbreviations: TF, tissue factor; VII, factor VII; VIla, activated factor VII; X, factor X; Xa, activated factor X; ProT, prothrombin; lla, thrombin. 


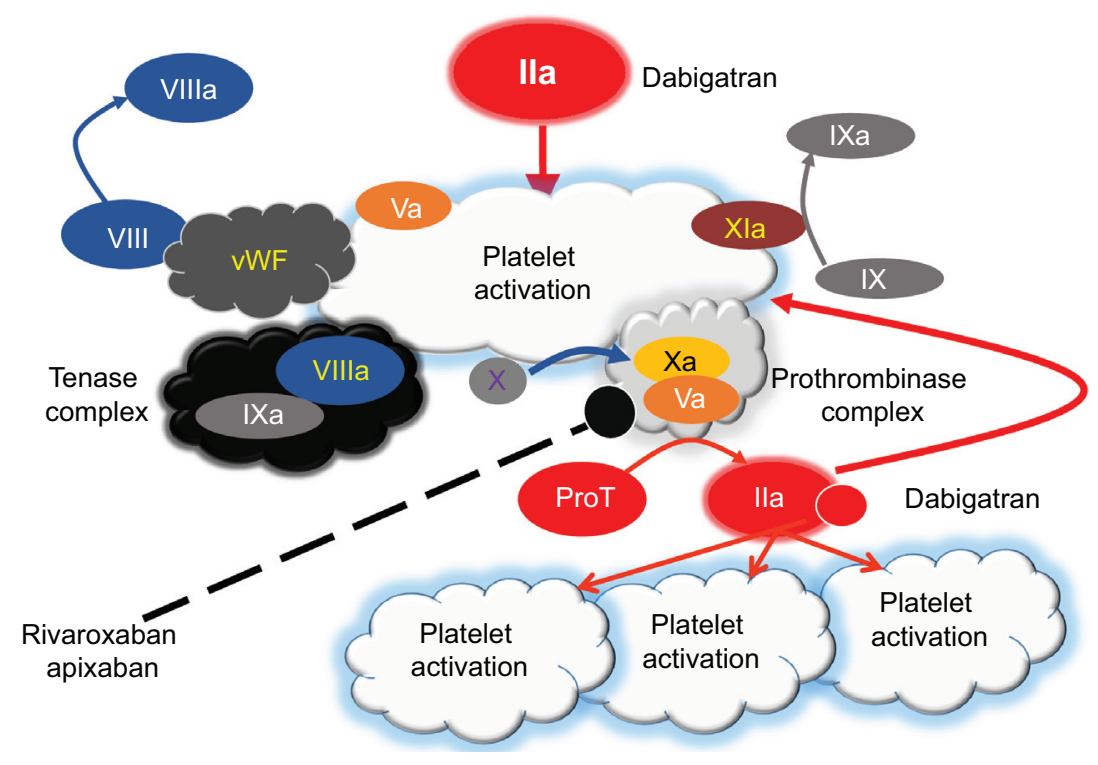

Figure 2 Amplification and propagation.

Abbreviations: VIIla, activated factor VIII; Ila, thrombin; VIII, factor VIII; Va, activated factor V; IXa, activated factor IX; Xla, activated factor XI; IX, factor IX; vWF, Von Willebrand factor; $X$, factor $\mathrm{X}$; $\mathrm{Xa}$, activated factor $\mathrm{X}$; ProT, prothrombin.

Drug Administration (FDA) has approved apixaban for the primary prevention of DVT following hip and knee replacement surgery.

\section{Primary thromboprophylaxis after hip surgery} Apixaban has been approved for the prevention of DVT after hip replacement surgery since $2014 .{ }^{13}$ This approval was primarily based on the Apixaban versus Enoxaparin for Thromboprophylaxis After Hip Replacement Trial (ADVANCE-3)

Table I Apixaban pharmacodynamics and pharmacokinetics

\begin{tabular}{|c|c|c|}
\hline Drug/mechanism of action & \multicolumn{2}{|c|}{ Apixaban/direct factor $\mathrm{Xa}$ inhibitor } \\
\hline $\begin{array}{l}\text { Protein binding/removed by } \\
\text { dialysis }\end{array}$ & \multicolumn{2}{|l|}{$87 \% /$ nondialyzable } \\
\hline$F(\%)$ & \multicolumn{2}{|c|}{$50 \%$ absorption in gastrointestinal tract } \\
\hline Tmax (hours) & \multicolumn{2}{|l|}{$3-4$} \\
\hline $\mathrm{Vd}(\mathrm{L})$ & \multicolumn{2}{|l|}{21} \\
\hline $\mathrm{T} 1 / 2$ (hours) & \multicolumn{2}{|l|}{$10-14$} \\
\hline Effects on half-life in various & $\mathrm{CrCl}>80 \mathrm{~mL} /$ minute & 15.1 \\
\hline \multirow[t]{3}{*}{ degrees of renal function } & $\mathrm{CrCl} 50-79 \mathrm{~mL} /$ minute & 14.6 \\
\hline & $\mathrm{CrCl} 30-49 \mathrm{~mL} /$ minute & 17.6 \\
\hline & $\mathrm{CrCl}<30 \mathrm{~mL} /$ minute & 17.3 \\
\hline Metabolism & \multicolumn{2}{|l|}{ CYP3A4/5 } \\
\hline $\begin{array}{l}\text { Effect of P-gp/ABCG2 on } \\
\text { metabolism }\end{array}$ & \multicolumn{2}{|l|}{$++/+$} \\
\hline Renal excretion (\%) & \multicolumn{2}{|l|}{23} \\
\hline Biliary excretion (\%) & \multicolumn{2}{|l|}{75} \\
\hline
\end{tabular}

Notes: + means low effect of ABCG2 on clearance of apixaban. ++ means moderate effect of P-gp.

Abbreviations: F, bioavailability; Tmax, time to reach maximum concentration $\mathrm{Vd}$, volume of distribution; $\mathrm{T} 1 \frac{2}{2}$, half-life; $\mathrm{CrCl}$, creatinine clearance; CYP3A4/5, cytochrome P450 3A4; P-gp/ABCG2, P-glycoprotein/ABCG2; P-gP, P-glycoprotein. in which 5,407 patients were randomly assigned to apixaban $2.5 \mathrm{mg}$ twice daily (started 12-24 hours after surgery) versus enoxaparin $40 \mathrm{mg}$ daily (started 12 hours before surgery) for 35 days. ${ }^{17}$ Patients with platelet counts lower than $100,000 / \mathrm{mm}^{3}$; hemoglobin level lower than $10 \mathrm{~g} / \mathrm{dL}$; brain, spinal, ophthalmologic, or major surgery or trauma within the past 90 days; daily aspirin doses above $165 \mathrm{mg}$; creatinine clearance $(\mathrm{CrCl})$ level lower than $30 \mathrm{~mL} /$ minute; and active hepatobiliary disease (based on an alanine aminotransferase or aspartate aminotransferase levels higher than two times the upper limit of normal or a total bilirubin level of at least 1.5 times the upper limit of normal), unless an alternative causative factor such as Gilbert syndrome was identified, were excluded. Efficacy outcomes (all VTE and death from any cause) occurred in $1.5 \%$ of patients in the apixaban group versus $3.9 \%$ of patients in the enoxaparin group with a relative risk (RR) of 0.36 (95\% confidence interval $[\mathrm{CI}]: 0.22-0.54 ; P<0.001)$. A secondary outcome of major and clinically relevant nonmajor bleeding occurred in $4.8 \%$ of those in the apixaban group and $5 \%$ of those in the enoxaparin group $(P=0.72) .{ }^{17}$ This study proved noninferiority of apixaban to enoxaparin for the prevention of VTE after THR.

\section{Primary thromboprophylaxis after knee surgery} Apixaban was evaluated in two large Phase III clinical trials the ADVANCE-1 and the ADVANCE-2 trials - which evaluated apixaban following TKR for 10-14 days. ${ }^{18,19}$ In the ADVANCE-1 trial, apixaban $2.5 \mathrm{mg}$ twice daily started 
12 hours after surgery (1,599 patients) for 10-14 days was compared to enoxaparin $30 \mathrm{mg}$ twice daily started 12 hours after surgery (1,596 patients) for 10-14 days. In the ADVANCE-2 study, apixaban $2.5 \mathrm{mg}$ twice daily started 12-24 hours after surgery for 10-14 days was compared to enoxaparin $40 \mathrm{mg}$ daily started 12 hours before surgery for 10-14 days. In both studies, bilateral venography was performed. The main exclusion criteria were similar to those in the ADVANCE- 3 trial. ${ }^{17}$ The primary efficacy outcome was a composite of asymptomatic and symptomatic DVT, nonfatal PE, and death from any cause. In the ADVANCE-1 trial, the primary efficacy outcome was $9 \%$ for the apixaban arm versus $8.8 \%$ for the enoxaparin arm (RR: 1.02 [95\% CI: $0.78-1.32$ ]; $P=0.06$ for noninferiority). The major bleeding and clinically relevant nonmajor bleeding event rates were $2.9 \%$ for the apixaban arm and $4.3 \%$ for the enoxaparin arm $(P=0.03)$. The apixaban arm did not meet the prespecified criteria for noninferiority compared to the patients taking enoxaparin $30 \mathrm{mg}$ twice daily. In the ADVANCE-2 trial, 1,528 (apixaban arm) and 1,529 (enoxaparin arm) patients were enrolled. The primary outcome was the composite of asymptomatic and symptomatic DVT, nonfatal PE, and all-cause death. Noninferiority criteria were met in the ADVANCE-2 trial with $15 \%$ of subjects in the apixaban arm and $24 \%$ of those in the enoxaparin arm (RR: 0.62 [95\% CI: $0.51-0.74]$; $P<0.0001)$. Major or clinically relevant nonmajor bleeding occurred in $4 \%$ of those in the apixaban arm and $5 \%$ of those in the enoxaparin arm $(P=0.09)$. Huang et al performed a meta-analysis of the ADVANCE-1 and ADVANCE-2 studies and concluded that apixaban is noninferior to enoxaparin and has a considerable safety profile advantage (major bleeding) in patients undergoing TKR surgery. ${ }^{20}$ Based on these studies, apixaban has been approved for primary thromboprophylaxis following TKR surgery. ${ }^{18-20}$

\section{Primary thromboprophylaxis in acutely ill medical patients}

Acutely ill patients hospitalized for myocardial infarction, stroke, pneumonia, decompensated heart failure, chronic obstructive lung disease exacerbation, and bacteremia are at high risk for VTE without prophylaxis. ${ }^{21}$ This risk could be as high as $50 \%$ in patients with acute hemiplegic stroke if no prophylaxis is used. ${ }^{22}$ The ACCP recommends pharmacological prophylaxis with heparins (LMWH or UFH) or fondaparinux in patients with no contraindication, and mechanical prophylaxis such as graduated compression stockings or intermittent pneumatic compression in patients with contraindications to pharmacological thromboprophylaxis. ${ }^{16}$ Apixaban has been evaluated for VTE prophylaxis in acutely ill patients. Goldhaber et al evaluated apixaban in a doubleblind, double-dummy, randomized trial of 6,528 acutely ill patients, comparing apixaban $2.5 \mathrm{mg}$ twice daily for 30 days versus subcutaneous enoxaparin $40 \mathrm{mg}$ daily for 6-14 days. ${ }^{23}$ Patients with active liver disease, anemia (hemoglobin $<9.0$ ), $\mathrm{CrCl}$ level lower than $30 \mathrm{~mL} /$ minute, surgery within the past 30 days, platelet count lower than $100,000 / \mathrm{mm}^{3}$, or daily aspirin consumption exceeding $165 \mathrm{mg}$ were excluded. The primary efficacy outcome (VTE or VTE-related deaths during the treatment period) was $2.71 \%(60 / 2211)$ in the apixaban arm versus $3.6 \%$ in the enoxaparin arm $(70 / 2,284)$ (RR: 0.87 [95\% CI: $0.62-1.23$ ]; $P=0.44$ ). The primary safety outcome of major bleeding (fatal, intracranial, other critical organ, decrease in hemoglobin, and transfusion of less than two units of packed red cells) occurred at a rate of $0.47 \%$ $(15 / 3,184)$ in the apixaban group and $0.18 \%(6 / 3,217)$ in the enoxaparin group (RR: 2.58 [95\% CI: $1.02-7.24]$; $P=0.04$ ). Even though the results are promising for VTE prevention in acutely ill patients, there was higher bleeding risk in the apixaban arm..$^{23}$ Although this study is thought-provoking, apixaban is not currently approved for the prevention of DVT in medically ill patients.

\section{Primary thromboprophylaxis in ambulatory cancer patients receiving chemotherapy}

Of all new VTE events, $20 \%$ are associated with cancer. ${ }^{24}$ Currently, the majority of care of cancer patients has been mainly delivered in the outpatient setting. In a retrospective study of over 17,000 patients, $78.3 \%$ of VTE events took place in the ambulatory setting versus $21.7 \%$ in the hospital setting. ${ }^{25}$ Many randomized studies have evaluated the role of ambulatory thromboprophylaxis in myeloma and solid cancer patients. ${ }^{26}$

Levine et $\mathrm{al}^{27}$ evaluated apixaban in a randomized, double-blind Phase II dose-ranging study investigating the efficacy and safety of apixaban (5 $\mathrm{mg}$ daily [32 patients], $10 \mathrm{mg}$ daily [30 patients], or $20 \mathrm{mg}$ daily [33 patients]) for 3 months versus placebo (30 patients) in those with metastatic cancer receiving chemotherapy. There were no major bleeds in the $5 \mathrm{mg}$ and $10 \mathrm{mg}$ daily groups and two major bleeds in the $20 \mathrm{mg}$ daily group (an overall $2.2 \%$ major bleeding rate in the apixaban group). Three placebo patients had symptomatic VTE, while the apixaban group had no symptoms. The study concluded that apixaban was well tolerated and supported the pursuit of Phase III clinical trials. However, the sample size was small and the study protocol included patients who were at low risk for bleeding. ${ }^{27}$ 


\section{Initial treatment of VTE in cancer patients}

Some cancers such as pancreatic, stomach, kidney, bladder, and uterine cancers confer higher risk for VTE than breast and colorectal cancers. In patients with pancreatic cancer and concomitant VTE, the risk of death within 1 year significantly increases by 2 - to 3 -fold, depending on the locoregional versus distant metastatic spread of the tumor. ${ }^{28}$ Patients with cancer are typically excluded from clinical trials of NOACs because of coagulopathy, thrombocytopenia, and uncertain prognosis. Currently, the American Society of Clinical Oncology, National Comprehensive Cancer Network, and ACCP recommend LMWH as the first-line and warfarin as the second-line treatment of VTE in patients with cancer. These guidelines currently do not recommend the use of NOACs in patients with cancer because of lacking evidence of their effectiveness. ${ }^{29-31}$ To date, there is no randomized trial of apixaban compared to LMWH for the treatment of VTE in cancer.

\section{Initial VTE treatment in the general population}

Because NOACs proved noninferior to heparin and VKA in the setting of atrial fibrillation, trials evolved to investigate their role in VTE. In a randomized, noninferiority, double-blind study (number $[\mathrm{n}]=5,400$ ), apixaban $10 \mathrm{mg}$ twice daily for 1 week followed by $5 \mathrm{mg}$ twice daily was compared to conventional therapy (enoxaparin followed by warfarin) for the acute treatment of VTE for 180 days. ${ }^{32}$ The major exclusion criteria for this trial were hemoglobin level lower than $9 \mathrm{mg} / \mathrm{dL}$, platelet count lower than 100,000/ $\mathrm{mm}^{3}$, serum creatinine level higher than $2.5 \mathrm{mg} / \mathrm{dL}$, or calculated $\mathrm{CrCl}$ level lower than $25 \mathrm{~mL} /$ minute. A first recurrent VTE or VTE-related death occurred in $2.3 \%$ of patients in the apixaban group versus $2.7 \%$ of patients in the conventional therapy group (RR: 0.84 [CI: 0.6-1.18]); $P<0.001$ for noninferiority). Major bleeding occurred in $0.6 \%$ of patients in the apixaban group and $1.8 \%$ of patients in the conventional therapy group (RR: 0.31 [CI: $0.17-0.55] ; P<0.001$ for noninferiority). It is noteworthy that the INR remained in the therapeutic range $61 \%$ of the time; however, the incidence of VTE when the INR was below 2.0 was not reported. ${ }^{32}$ At present, apixaban is not approved for this indication.

\section{Extended VTE treatment in the general population}

Agnelli et $\mathrm{al}^{33}$ examined two doses of apixaban $(2.5 \mathrm{mg}$ and $5 \mathrm{mg}$ twice daily) versus placebo in patients with VTE who had completed 6-12 months of anticoagulation therapy.
Patients were excluded if they required daily aspirin doses above $165 \mathrm{mg}$, had a hemoglobin level lower than $9 \mathrm{mg} / \mathrm{dL}$, a platelet count lower than $100,000 / \mathrm{mm}^{3}$, serum creatinine level higher than $2.5 \mathrm{mg} / \mathrm{dL}$, calculated $\mathrm{CrCl}$ level lower than $25 \mathrm{~mL} /$ minute, or elevated liver enzymes (two times the upper normal limit). The risk for recurrent VTE or death from any cause was $3.8 \%$ in the apixaban $2.5 \mathrm{mg}$ group, $4.2 \%$ in the apixaban $5 \mathrm{mg}$ group, and $11.6 \%$ in the placebo group with the RR in the apixaban $2.5 \mathrm{mg}$ group versus the placebo group calculated as 0.33 (95\% CI: $0.22-0.48$ ), and the apixaban $5 \mathrm{mg}$ group versus the placebo group calculated as 0.36 (95\% CI: 0.25-0.53). The major bleeding risk was $0.2 \%$ in the apixaban $2.5 \mathrm{mg}$ group, $0.1 \%$ in the apixaban $5 \mathrm{mg}$ group, and $0.5 \%$ in the placebo group. In the apixaban $2.5 \mathrm{mg}$ group versus the placebo group, the apixaban $5 \mathrm{mg}$ group versus the placebo group, and the apixaban $2.5 \mathrm{mg}$ group versus the $5 \mathrm{mg}$ group, the RRs were 0.49 (95\% CI: 0.09-2.64), 0.25 (95\% CI: 0.03-2.24), and 1.93 (95\% CI: $0.18-21.25)$, respectively. This study showed that apixaban $2.5 \mathrm{mg}$ twice daily and $5 \mathrm{mg}$ twice daily reduced the risk for recurrent VTE without increasing risk for bleeding. ${ }^{33}$

\section{Monitoring of apixaban}

Laboratory testing to assess the effect of apixaban on coagulation parameters such as activated partial thromboplastin time (aPTT), INR, and prothrombin time (PT) have been conducted. However, the clinical significance of its effects on coagulation parameters is unknown. In a single-dose range study, ${ }^{34} 10 \mathrm{mg}, 25 \mathrm{mg}$, and $50 \mathrm{mg}$ of apixaban increased the aPTT and INR, and modified the PT by 1.2-, 1.6-, and 2.9 -fold. These results were consistent with the inhibition of FXa. ${ }^{34}$ In a study of 42 healthy individuals, the effect of apixaban on coagulation parameters was reported. The result showed a concentration-dependent prolongation of PT, dilute PT, and aPTT. The same study found no effect on ecarin clotting time, thrombin time, and reptilase time; however, a concentration-dependent decrease in chromogenic anti-Xa assays was observed. ${ }^{35}$ A recent multicenter study examined the effect of different concentrations of apixaban on coagulation parameters. Apixaban linearly increased PT and aPTT, and demonstrated low sensitivity for a large panel of PT/aPTT reagents, while chromogenic anti-Xa assay was more sensitive. ${ }^{36}$ Dilute thrombin time is not an appropriate measure to test the anticoagulant effects of apixaban. Based on the available literature, the chromogenic anti-Xa assay is considered more sensitive for the detection of the anticoagulant activity of apixaban. ${ }^{37}$ Overall, some 
tests such as dilute PT, the Heptest, ecarin clotting time, and prothrombinase-induced clotting time lack supportive data and are not approved by the US FDA. ${ }^{38}$

\section{Perioperative management of apixaban therapy}

There are no guidelines for the management of NOACs in perioperative or emergent surgery settings. In emergent cases, activated charcoal (if apixaban was ingested within 2 hours) and the administration of four-factor prothrombin complex concentrates (PCCs) to overwhelm the anticoagulant properties of apixaban can be used. ${ }^{39}$ In cases of elective surgery, risk of perioperative thromboembolism and bleeding should be assessed. This assessment determines the need for perioperative bridging with short-acting anticoagulants in the immediate perioperative setting. Patients with mechanical heart valves, a recent ( $<6$ months) history of stroke, a CHADS2 (Congestive Heart Failure, Hypertension, Age $>75$ years, Diabetes mellitus, Stroke history) score higher than 5, a recent history of VTE ( $<3$ months), and the presence of thrombophilia (positive for antiphospholipid antibodies, proteins $\mathrm{C}$ and $\mathrm{S}$, and antithrombin deficiency) carry a risk exceeding $10 \%$ per year for arterial thromboem- bolism (ATE) and 10\% per month for VTE. ${ }^{40,41}$ These patients require bridging with short-acting anticoagulants. Patients with bileaflet aortic valve disease (at major stroke risk), a CHADS2 score of 3 or 4, VTE within the past 3-12 months, and active cancer disease are considered to be at intermediate risk (4\%-10\% per year risk for ATE or $4 \%-10 \%$ per month risk for VTE). This group may need bridging if bleeding risk is low. Finally, patients with bileaflet aortic valve disease (without stroke risk), a CHADS2 score of 0-2, and a remote VTE event history more than 1 year in the past are considered to be at low risk ( $<4 \%$ per year risk for ATE or $<2 \%$ per month risk for VTE). This low-risk group does not require bridging. ${ }^{40,41}$ For patients taking apixaban, $\mathrm{CrCl}$ should be assessed to determine the duration of apixaban interruption before surgery. This duration, depending on $\mathrm{CrCl}$ and the procedure bleeding risk, varies between 24 hours and 96 hours (Table 2). ${ }^{42-44}$ Again, there is a clear lack of guidelines for the resumption of apixaban after procedures. For low-risk procedures, apixaban may be resumed within 24 hours; for high-risk procedures, apixaban may be resumed within 48-72 hours. For patients who are unable to take oral medications in the immediate postoperative period, enoxaparin $40 \mathrm{mg}$ once daily has been suggested for VTE prophylaxis. ${ }^{41}$

Table 2 Interruption/holding times for procedures

\begin{tabular}{|c|c|c|c|}
\hline & $\mathrm{CrCl}$ (mL/minute) & $\begin{array}{l}\text { Low-risk or minor surgery } \\
\text { (procedures with a } 2 \text {-day risk for major } \\
\text { bleeding } 0 \%-2 \% \text { ) }\end{array}$ & $\begin{array}{l}\text { High-risk or major surgery } \\
\text { (procedures with a } 2 \text {-day risk } \\
\text { for major bleeding } 2 \%-4 \% \text { ) }\end{array}$ \\
\hline Apixaban & $\begin{array}{l}>50 \\
30-50 \\
<30\end{array}$ & $\begin{array}{l}24 \text { hours } \\
24-48 \text { hours } \\
48 \text { hours }\end{array}$ & $\begin{array}{l}48 \text { hours } \\
72-96 \text { hours } \\
96 \text { hours }\end{array}$ \\
\hline $\begin{array}{l}\text { Types of surgical } \\
\text { procedure }\end{array}$ & & $\begin{array}{l}\text { - Cholecystectomy } \\
\text { - Abdominal hernia repair } \\
\text { - Abdominal hysterectomy } \\
\text { - Coronary angiography/percutaneous } \\
\text { coronary intervention } \\
\text { - Electrophysiologic testing } \\
\text { - Pacemaker/cardiac defibrillator insertion } \\
\text { - Gastrointestinal endoscopy } \pm \text { biopsy, } \\
\text { enteroscopy, biliary/pancreatic stent without } \\
\text { - } \text { - Minor plastic surgery (carpal tunnel repair) } \\
\text { - Minor orthopedic surgery/arthroscopy } \\
\text { - Minor gynecologic surgery (dilation and curettage) } \\
\text { - Minor dental procedures (extractions) } \\
\text { - Minor skin procedures (cancer excision) } \\
\text { - Minor eye procedures (cataract) }\end{array}$ & $\begin{array}{l}\text { - Major cardiac surgery (surgical } \\
\text { heart valve replacement/ } \\
\text { coronary artery bypass grafting) } \\
\text { - Major neurosurgical procedures } \\
\text { - Major cancer surgery (head and } \\
\text { neck/abdominal/thoracic) } \\
\text { - Major orthopedic surgery (joint } \\
\text { replacement/laminectomy) } \\
\text { - Major urologic surgery } \\
\text { (prostate/bladder resection) } \\
\text { - Major vascular surgery } \\
\text { - Kidney biopsy } \\
\text { - Polypectomy, variceal treatment, } \\
\text { biliary sphincterotomy, } \\
\text { pneumatic dilation } \\
\text { - Endoscopically guided fine- } \\
\text { needle aspiration }\end{array}$ \\
\hline
\end{tabular}

Abbreviation: $\mathrm{CrCl}$, creatinine clearance. 


\section{Recommended dosing and dose adjustments}

For prophylaxis of DVT following hip or knee replacement surgery, the recommended dose of apixaban is $2.5 \mathrm{mg}$ taken orally twice daily for 35 days in patients undergoing hip replacement surgery and 12 days in patients undergoing knee replacement surgery. ${ }^{13}$ The first dose should be given 12-24 hours after surgery. Special dosing instructions apply for patients who are taking apixaban for atrial fibrillation, patients with chronic kidney disease, extreme body weight, elderly patients, and in pregnant women.

\section{Apixaban use in special populations}

To date, we are not aware of any studies specifically examining apixaban use in patients with chronic kidney disease, extreme body weight, elderly patients, and in pregnant women. The dosing adjustment for the prevention of systemic embolism in patients with nonvalvular atrial fibrillation with any two of the following conditions - moderate renal impairment (serum creatinine $\geq 1.5 \mathrm{mg} / \mathrm{dL}$ ), age $\geq 80$ years, or body weight $\leq 60 \mathrm{~kg}$ - is $2.5 \mathrm{mg}$ twice daily (Table 3 ). The recommended dose for nonvalvular atrial fibrillation patients with end-stage renal disease maintained on hemodialysis is $5 \mathrm{mg}$ twice daily; however, if the patient is over 80 years of age or has a body weight of less than $60 \mathrm{~kg}$, the dose should be reduced by $50 \%$ or $2.5 \mathrm{mg}$ twice daily..$^{13}$ The absence of data in special populations may not be resolved, as these population are subjected to exclusion criteria from clinical trials and its use in such groups requires an evaluation of the risks versus benefits.

\section{Management of bleeding complications}

The rate of bleeding is $3.8 \%$ per year with aspirin and $4.5 \%$ per year with apixaban therapy in patients with atrial fibrillation (hazard ratio [HR] with apixaban: 1.18 [95\% CI: 0.92-1.51]; $P=0.19) .{ }^{45}$ Compared to warfarin, NOACs significantly reduce risk for intracranial hemorrhage by 56\% (RR: 0.44 [95\% CI: $0.37-0.51]$ ) but, when compared to aspirin, apixaban poses a similar risk for intracranial hemorrhage (RR: 0.84 [95\% CI: 0.38-1.87]). ${ }^{46}$ Traditionally, vitamin $\mathrm{K}$ and/or fresh frozen plasma have been used successfully to reverse the anticoagulant effect of warfarin in patients with bleeding issues or for procedures. ${ }^{47,48}$ Currently, there is no antidote to reverse the anticoagulant effect of apixaban; however, prohemostatic agents may be used for bleeding situations. The administration of different prohemostatic agents also necessitates agent availability and approval by regulatory agencies. No randomized trial assesses the reversibility of bleeding associated with apixaban. In an in vitro study, PCCs (50 IU/kg), activated PCCs (75 IU/kg), or activated recombinant factor VII (rFVIIa) $(270 \mu \mathrm{g} / \mathrm{kg})$ were used to investigate the potential reversibility of apixaban rFVIIa-corrected prolonged clotting

Table 3 Apixaban drug interactions

\begin{tabular}{|c|c|c|}
\hline Interacting drugs & Effect & Clinical implications \\
\hline $\begin{array}{l}\text { Combined P-gP and strong CYP3A4/5 inhibitors } \\
\text { - Antiretroviral (protease inhibitor) } \\
\text { o Ritonavir } \\
\text { - Vasopressin receptor antagonist (Conivaptan) } \\
\text { - Azole antifungals } \\
\text { o Ketoconazole } \\
\text { ○ Itraconazole } \\
\text { - Macrolide antibiotic (clarithromycin) }\end{array}$ & $\begin{array}{l}\text { Increase apixaban } \\
\text { serum concentration }\end{array}$ & $\begin{array}{l}\text { Decrease apixaban to } 2.5 \mathrm{mg} \text { BID } \\
\text { (If patient is already on apixaban } 2.5 \mathrm{mg} \text { BID } \\
\text { due to the presence any two of the following: } \\
\text { - age } \geq 80 \text { years } \\
\text { - body weight } \leq 60 \mathrm{~kg} \\
\text { - serum creatinine } \geq \mathrm{I} .5 \mathrm{mg} / \text { day, } \\
\text { then avoid use of apixaban) }\end{array}$ \\
\hline $\begin{array}{l}\text { Combined P-gp and strong CYP3A4/5 inducers } \\
\text { - Carbamazepine } \\
\text { - St John's wort } \\
\text { - Dabrafenib }\end{array}$ & $\begin{array}{l}\text { Decrease apixaban } \\
\text { serum concentration }\end{array}$ & Decreased antithrombotic efficacy \\
\hline $\begin{array}{l}\text { Rifampin } 600 \text { mg daily } \\
\text { Phenytoin } \\
\text { Antiplatelet agents } \\
\text { - Aspirin } \\
\text { - Clopidogrel } \\
\text { - Prasugrel } \\
\text { - Ticagrelor }\end{array}$ & $\begin{array}{l}\text { Decrease apixaban } \\
\text { serum concentration } \\
\text { Increase in bleeding risk is } \\
\text { dose dependent }\end{array}$ & Possible decrease in efficacy \\
\hline
\end{tabular}

Abbreviations: P-gp, P-glycoprotein; CYP3A4/5, cytochrome P450 3A4; BID, twice daily. 
time better than PCC or aPCC. ${ }^{49}$ In a rabbit model of bleeding induced by apixaban, the effects of rFVIIa $240 \mu \mathrm{g} / \mathrm{kg}$, PCCs $60 \mathrm{IU} / \mathrm{kg}$, or fibrinogen concentrate $300 \mathrm{mg} / \mathrm{kg}$ on PT, bleeding time, clotting time, and thrombin generation time were studied. rVIIa decreased bleeding time, but failed to improve blood loss. PCC and rVIIa both shortened the lag time of thrombin generation time and also decreased PT and clotting time. ${ }^{50}$ The net clinical effect of this study was the correction of coagulation parameters in a heterogeneous fashion, and their effect in humans is unknown. The administration of prohemostatic agents required a consideration of risks versus benefits. Clinicians should consider the thromboembolism risk of $1.8 \%$ (95\% CI: $1.0-3.0)$ and $0.7 \%$ (95\% CI: $0-2.4)$ in patients treated with four-factor PCC and three-factor PCC, respectively. ${ }^{51}$ With rVIIa, the rates of ATE events were higher than with placebo (5.5\% versus $3.2 \%$, respectively; $P=0.003$ ), and the rates of VTE events were similar among subjects who received rFVIIa and those who received placebo $(5.3 \%$ versus $5.7 \%$, respectively). The rates of thromboembolic complications were higher among those aged 65 years and older (9.0\% in the rFVIIa group versus 3.8\% in the placebo group; $P=0.003)$; the rates were especially high among those 75 years of age or older $(10.8 \%$ versus $4.1 \% ; P=0.02){ }^{52}$

In apixaban-treated patients presenting with either acute bleeding that was considered clinically significant, major bleeding, or life-threatening bleeding, apixaban should be discontinued, and local measures to control the bleeding site and to measure baseline coagulation should be implemented. Volume resuscitation, administration of four-factor PCC (25-50 U/kg), and hematologist consultation should be considered for patients with low blood pressure and major bleeding. ${ }^{53}$ Protein binding of $87 \%$ with apixaban restricts the use of hemodialysis. ${ }^{54}$ The effect of recombinant protein antidote r-Antidote (PRT064445) on FXa-I has been investigated in animal models. ${ }^{55} \mathrm{r}$-Antidote reversed the inhibition of FXa by direct FXa-I in a dose-dependent fashion and corrected the prolongation of ex vivo clotting times by FXa-I. The authors concluded that $\mathrm{r}$-Antidote has the potential to be used as an antidote for FXa-Is. ${ }^{55}$ It is not approved for use at present.

\section{Drug-drug interactions with apixaban}

Apixaban is primarily metabolized by cytochrome $\mathrm{P} 450$ (CYP) enzyme CYP 3A4/5, with a minor pathway from CYP1A2, CYP2C8, CYP2C9, CYP2C19, and CYP2J2. Apixaban is also a substrate for $\mathrm{P}$-gp and breast cancer resistance protein. ${ }^{56} \mathrm{P}$-gp is a transport protein that functions as an efflux pump to prevent the absorption of certain drugs such as apixaban. Inhibitors and inducers of P-gp will increase and decrease plasma apixaban levels. ${ }^{57}$ Common dietary supplements that have anticoagulant properties should be avoided, such as bladderwrack, gamma linoleic acid, glucosamine, and melatonin. Other dietary supplements that may decrease platelet aggregation should be avoided such as boldo, bromelain, budrock, caffeine, clove, cod liver oil, coltsfoot, danshen, fenugreek, fish oil, flaxseed, ginger, ginkgo, ginseng, milk thistle, turmeric, vitamin $\mathrm{E}$ ( $>800$ units per day), and willow bark. ${ }^{58}$ Supplements with thrombolytic activity such as nattokinase should also not be taken with apixaban. ${ }^{58}$ Food may delay the Tmax of apixaban, but no adjustment is required. Table 3 lists some of apixaban's drugdrug interactions. ${ }^{14}$ It is imperative to note that no clinical studies have examined specific apixaban interactions. Some combined CYP3A4 inhibitors and P-gp inhibitors such as azole antifungals, conivaptan, ritonavir (protease inhibitor), and clarithromycin can substantially increase the serum concentration of apixaban, and a dose reduction of apixaban is then required. Health care providers should consider increasing the frequency of patient monitoring for bleeding if drug combinations cannot be avoided. Combined P-gp and strong CYP3A4 inducers such as carbamazepine, St John's wort, dabrafenib, rifampin, and phenytoin can potentially decrease the anticoagulant efficacy of apixaban, so their combination with apixaban should be avoided. ${ }^{59}$

Nearly $30 \%$ of community patients in the US report use of aspirin, and as many as $4 \%$ may use clopidogrel. ${ }^{60}$ In the APPRAISE (Apixaban for Prevention of Acute Ischemic and Safety Events) trial, ${ }^{61}$ the rate of major and clinically relevant nonmajor bleeding was $3 \%$ in the placebo group, $5.7 \%$ in the group taking apixaban $2.5 \mathrm{mg}$ twice daily, and $7.9 \%$ in the group taking apixaban $10 \mathrm{mg}$ daily. In this study, all patients received aspirin ( $<165 \mathrm{mg}$ per day) and $75 \%$ received dual antiplatelet therapy. ${ }^{61}$ In the APPRAISE-2 $(n=10,800)$ trial, ${ }^{62}$ the rate of major bleeding and clinically relevant nonmajor bleeding was $3.2 \%$ in the apixaban arm and $1.2 \%$ in the placebo group (HR: $2.62 ; P<0.001$ ), which led to the termination of the study after enrolling almost 7,400 patients. In this trial, all patients were taking aspirin and $80 \%$ were taking dual antiplatelets. ${ }^{62}$ Currently, there are no clinical trials of apixaban in combination with the newer antiplatelet agents such as prasugrel and ticagrelor, but increased risk for bleeding may be expected with the combination. Therefore, patients on triple therapy (dual antiplatelet therapy + apixaban) should be monitored closely.

\section{Transition to other anticoagulants}

No randomized trials assess the transitioning of apixaban to other anticoagulants. Basically, for bridging to a shorter-acting 
anticoagulant in the preoperative period or for patients transitioning to LMWH or intravenous UFH, the first dose should be given when the next dose of apixaban was scheduled to be administered. For patients transitioning to VKA because of cost issues, LMWH or intravenous UFH should be started in conjunction with VKA when the next dose of apixaban is due. For patients being transitioned to apixaban from $\mathrm{LMWH}$, the first dose should be given before the next dose of scheduled LMWH. For patients on intravenous UFH, apixaban can be started when aPTT normalizes. When patients transition from injectable FXa-I (fondaparinux), apixaban may be started up to 2 hours before the next scheduled dose of FXa-I was to be given. For patients transitioning from VKA to apixaban, the INR will need to be monitored; when the INR is lower than 2.0, apixaban can be initiated. ${ }^{14}$

\section{Patient education}

As NOACs are introduced into the market, clinicians must become more familiar with PD and PK properties and they should screen for drug interactions prior to initiation to prevent increased risk of bleeding complications. Clinicians should be in direct communication with other providers involved in patient care. Comprehensive patient education that covers the following topics should be conducted:

- Reminders for the exact dose and its frequency and duration

- Instructions for missed doses and directions to not double the dose

- Periodic monitoring of renal and hemoglobin levels

- If pregnancy is planned, as well as if it occurs

- Plan of action for planned procedures such as dental or eye procedures or major surgery

- Informing all involved health care providers if a medication is added or stopped

- Importance of compliance

- Importance of carrying a current and up-to-date list of medications

- Common signs and symptoms of bleeding and a plan of action

- Fall and injury prevention (education on medic alert methods)

- Discussion on taking nonsteroidal anti-inflammatory agents

\section{Current approval status}

Apixaban has been approved to reduce the risk of stroke or systemic embolism in patients with nonvalvular atrial fibrillation and for prophylaxis of DVT following THR or TKR in the US, Canada, Australia, and the European Union.

\section{Conclusion}

Apixaban has shown noninferiority to warfarin in the setting of stroke prevention in nonvalvular atrial fibrillation and has been studied for the prevention and treatment of VTE. Apixaban does not necessitate frequent laboratory monitoring, but patients should be followed closely. Patient education that focuses on drug interactions is imperative for successful therapy with apixaban. Utilization of apixaban for cancer prevention and treatment of cancer-associated thrombosis is lacking. Other areas of uncertainty include bridging for the perioperative setting and requirements for neuroaxial anesthesia when anticoagulant properties of apixaban might be difficult to interpret.

\section{Acknowledgment}

The authors thank the University of Texas MD Anderson Cancer Center's Department of Scientific Publications for editing this paper.

\section{Disclosure}

The authors report no conflicts of interest in this work.

\section{References}

1. Yeh CH, Gross PL, Weitz JI. Evolving use of new oral anticoagulants for treatment of venous thromboembolism. Blood. 2014;124(7):1020-1028.

2. Tun NM, Oo TH. Prevention and treatment of venous thromboembolism with new oral anticoagulants: a practical update for clinicians. Thrombosis. 2013;2013:183616.

3. Mackman N, Tilley RE, Key NS. Role of the extrinsic pathway of blood coagulation in hemostasis and thrombosis. Arterioscler Thromb Vasc Biol. 2007;27(8):1687-1693.

4. Ahrens I, Peter K, Lip GY, Bode C. Development and clinical applications of novel oral anticoagulants. Part II. Drugs under clinical investigation. Discov Med. 2012;13(73):445-450.

5. Weitz JI, Bates SM. New anticoagulants. J Thromb Haemost. 2005;3(8): 1843-1853.

6. Scaglione F. New oral anticoagulants: comparative pharmacology with vitamin K antagonists. Clin Pharmacokinet. 2013;52(2):69-82.

7. Samama MM, Bara L, Gouin-Thibault I. New data on the pharmacology of heparin and low molecular weight heparins. Drugs. 1996;52 Supp1 7:8-14; discussion 14-15.

8. Turpie AG. New oral anticoagulants in atrial fibrillation. Eur Heart $J$. 2008;29(2):155-165.

9. Deeks ED. Apixaban: a review of its use in the prevention of venous thromboembolism after knee or hip replacement surgery. Drugs. 2012;72(9):1271-1291.

10. Mueck W, Schwers S, Stampfuss J. Rivaroxaban and other novel oral anticoagulants: pharmacokinetics in healthy subjects, specific patient populations and relevance of coagulation monitoring. Thromb $J$. 2013;11(1):10.

11. Mahan CE, Fanikos J. New antithrombotics: the impact on global health care. Thromb Res. 2011;127(6):518-524.

12. Kubitza D, Becka M, Mueck W, et al. Effects of renal impairment on the pharmacokinetics, pharmacodynamics and safety of rivaroxaban, an oral, direct Factor Xa inhibitor. Br J Clin Pharmacol. 2010; 70(5):703-712.

13. ELIQUIS ${ }^{\circledR}$ (apixaban) tablets for oral use [prescribing information]. Princeton, NJ: Bristol-Myers Squbb Company; 2014. Available from: http://packageinserts.bms.com/pi/pi_eliquis.pdf. Accessed July 1, 2014. 
14. Geerts WH, Bergqvist D, Pineo GF, et al; American College of Chest Physicians. Prevention of venous thromboembolism: American College of Chest Physicians Evidence-Based Clinical Practice Guidelines (8th Edition). Chest. 2008;133(6 Suppl):381S-453S.

15. O'Reilly RF, Burgess IA, Zicat B. The prevalence of venous thromboembolism after hip and knee replacement surgery. Med J Aust. 2005;182(4):154-159.

16. Guyatt GH, Akl EA, Crowther M, Gutterman DD, Schuünemann HJ; American College of Chest Physicians Antithrombotic Therapy and Prevention of Thrombosis Panel. Executive summary: Antithrombotic Therapy and Prevention of Thrombosis, 9th ed: American College of Chest Physicians Evidence-Based Clinical Practice Guidelines. Chest. 2012;141(2 Suppl):7S-47S.

17. Lassen MR, Gallus A, Raskob GE, Pineo G, Chen D, Ramirez LM; ADVANCE-3 Investigators. Apixaban versus enoxaparin for thromboprophylaxis after hip replacement. $N$ Engl J Med. 2010;363(26): 2487-2498.

18. Lassen MR, Raskob GE, Gallus A, Pineo G, Chen D, Portman RJ. Apixaban or enoxaparin for thromboprophylaxis after knee replacement. N Engl J Med. 2009;361(6):594-604.

19. Lassen MR, Raskob GE, Gallus A, Pineo G, Chen D, Hornick P; ADVANCE-2 investigators. Apixaban versus enoxaparin for thromboprophylaxis after knee replacement (ADVANCE-2): a randomised double-blind trial. Lancet. 2010;375(9717):807-815.

20. Huang J, Cao Y, Liao C, Wu L, Gao F. Apixaban versus enoxaparin in patients with total knee arthroplasty. A meta-analysis of randomised trials. Thromb Haemost. 2011;105(2):245-253.

21. Spyropoulos AC, Mahan C. Venous thromboembolism prophylaxis in the medical patient: controversies and perspectives. Am JMed.2009;122(12): 1077-1084

22. Kelly J, Rudd A, Lewis R, Hunt BJ. Venous thromboembolism after acute stroke. Stroke. 2001;32(1):262-267.

23. Goldhaber SZ, Leizorovicz A, Kakkar AK, et al; ADOPT Trial Investigators. Apixaban versus enoxaparin for thromboprophylaxis in medically ill patients. $N$ Engl J Med. 2011;365(23):2167-2177.

24. Heit JA. Cancer and venous thromboembolism: scope of the problem. Cancer Control. 2005;12 Suppl 1:5-10.

25. Khorana AA, Dalal M, Tangirala K, Miao R. Higher incidence of venous thromboembolism in the outpatient versus the inpatient setting among US cancer patients [Abstract]. Blood. 2013;118: Abstract 674 .

26. Di Nisio M, Porreca E, Ferrante N, Otten HM, Cuccurullo F, Rutjes AW. Primary prophylaxis for venous thromboembolism in ambulatory cancer patients receiving chemotherapy. Cochrane Database Syst Rev. 2012;2:CD008500.

27. Levine $\mathrm{MN}, \mathrm{Gu} \mathrm{C}$, Liebman HA, et al. A randomized phase II trial of apixaban for the prevention of thromboembolism in patients with metastatic cancer. J Thromb Haemost. 2012;10(5):807-814.

28. Wun T, White RH. Venous thromboembolism (VTE) in patients with cancer: epidemiology and risk factors. Cancer Invest. 2009;27 Suppl 1: 63-74.

29. Lyman GH, Khorana AA, Kuderer NM, et al; American Society of Clinical Oncology Clinical Practice. Venous thromboembolism prophylaxis and treatment in patients with cancer: American Society of Clinical Oncology clinical practice guideline update. J Clin Oncol. 2013;31(17):2189-2204.

30. Streiff MB, Bockenstedt PL, Cataland SR, et al; National comprehensive cancer network. Venous thromboembolic disease. J Natl Compr Canc Netw. 2013;11(11):1402-1429.

31. Kearon C, Akl EA, Comerota AJ, et al; American College of Chest Physicians. Antithrombotic therapy for VTE disease: Antithrombotic Therapy and Prevention of Thrombosis, 9th ed: American College of Chest Physicians Evidence-Based Clinical Practice Guidelines. Chest. 2012;141(2 Suppl):e419S-e494S.

32. Agnelli G, Buller HR, Cohen A, et al; AMPLIFY Investigators. Oral apixaban for the treatment of acute venous thromboembolism. $N$ Engl J Med. 2013;369(9):799-808.
33. Agnelli G, Buller HR, Cohen A, et al; PLIFY-EXT Investigators. Apixaban for extended treatment of venous thromboembolism. NEngl J Med. 2013;368(8):699-708.

34. Frost C, Wang J, Nepal S, et al. Apixaban, an oral, direct factor Xa inhibitor: single dose safety, pharmacokinetics, pharmacodynamics and food effect in healthy subjects. Br J Clin Pharmacol. 2013;75(2): 476-487.

35. Douxfils J, Chatelain C, Chatelain B, Dogné JM, Mullier F. Impact of apixaban on routine and specific coagulation assays: a practical laboratory guide. Thromb Haemost. 2013;110(2):283-294.

36. Gouin-Thibault I, Flaujac C, Delavenne X, et al. Assessment of apixaban plasma levels by laboratory tests: suitability of three anti-Xa assays. A multicentre French GEHT study. Thromb Haemost. 2014;111(2):240-248.

37. Wood P. New oral anticoagulants: an emergency department overview. Emerg Med Australas. 2013;25(6):503-514.

38. Miyares MA, Davis K. Newer oral anticoagulants: a review of laboratory monitoring options and reversal agents in the hemorrhagic patient. Am J Health Syst Pharm. 2012;69(17):1473-1484.

39. Heidbuchel $\mathrm{H}$, Verhamme P, Alings $M$, et al. EHRA practical guide on the use of new oral anticoagulants in patients with non-valvular atrial fibrillation: executive summary. Eur Heart J. 2013;34(27):2094-2106.

40. Douketis JD, Spyropoulos AC, Spencer FA, et al; American College of Chest Physicians. Perioperative management of antithrombotic therapy: Antithrombotic Therapy and Prevention of Thrombosis, 9th ed: American College of Chest Physicians Evidence-Based Clinical Practice Guidelines. Chest. 2012;141(2 Suppl):e326S-e350S.

41. Spyropoulos AC, Douketis JD. How I treat anticoagulated patients undergoing an elective procedure or surgery. Blood. 2012;120(15): 2954-2962.

42. Douketis JD, Johnson JA, Turpie AG. Low-molecular-weight heparin as bridging anticoagulation during interruption of warfarin: assessment of a standardized periprocedural anticoagulation regimen. Arch Intern Med. 2004;164(12):1319-1326.

43. Spyropoulos AC, Turpie AG, Dunn AS, et al; REGIMEN Investigators. Clinical outcomes with unfractionated heparin or low-molecularweight heparin as bridging therapy in patients on long-term oral anticoagulants: the REGIMEN registry. J Thromb Haemost. 2006;4(6): $1246-1252$.

44. Nutescu EA. Oral anticoagulant therapies: balancing the risks. $\mathrm{Am} \mathrm{J}$ Health Syst Pharm. 2013;70(10 Suppl 1):S3-S11.

45. Flaker GC, Eikelboom JW, Shestakovska O, et al. Bleeding during treatment with aspirin versus apixaban in patients with atrial fibrillation unsuitable for warfarin: the apixaban versus acetylsalicylic acid to prevent stroke in atrial fibrillation patients who have failed or are unsuitable for vitamin $\mathrm{K}$ antagonist treatment (AVERROES) trial. Stroke. 2012;43(12):3291-3297.

46. Hankey GJ. Intracranial hemorrhage and novel anticoagulants for atrial fibrillation: what have we learned? Curr Cardiol Rep. 2014; 16(5):480

47. Rashidi A, Tahhan HR. Fresh frozen plasma dosing for warfarin reversal: a practical formula. Mayo Clin Proc. 2013;88(3):244-250.

48. Meehan R, Tavares M, Sweeney J. Clinical experience with oral versus intravenous vitamin K for warfarin reversal. Transfusion. 2013; 53(3):491-498; quiz 490.

49. Escolar G, Fernandez-Gallego V, Arellano-Rodrigo E, et al. Reversal of apixaban induced alterations in hemostasis by different coagulation factor concentrates: significance of studies in vitro with circulating human blood. PLoS One. 2013;8(11):e78696.

50. Martin AC, Le Bonniec B, Fischer AM, et al. Evaluation of recombinant activated factor VII, prothrombin complex concentrate, and fibrinogen concentrate to reverse apixaban in a rabbit model of bleeding and thrombosis. Int J Cardiol. 2013;168(4):4228-4233.

51. 49. Dentali F, Marchesi C, Pierfranceschi MG, et al. Safety of prothrombin complex concentrates for rapid anticoagulation reversal of vitamin $\mathrm{K}$ antagonists. A meta-analysis. Thromb Haemost. 2011; 106(3):429-438. 
52. Levi M, Levy JH, Andersen HF, Truloff D. Safety of recombinant activated factor VII in randomized clinical trials. NEngl JMed. 2010;363(19) 1791-1800.

53. Ward C, Conner G, Donnan G, Gallus A, McRae S. Practical management of patients on apixaban: a consensus guide. Thromb J. 2013; 11(1):27.

54. Akwaa F, Spyropoulos AC. Treatment of bleeding complications when using oral anticoagulants for prevention of strokes. Curr Treat Options Cardiovasc Med. 2013;15(3):288-298.

55. Lu G, DeGuzman FR, Hollenbach SJ, et al. A specific antidote for reversal of anticoagulation by direct and indirect inhibitors of coagulation factor Xa. Nat Med. 2013;19(4):446-451.

56. Keating GM. Apixaban: a review of its use for reducing the risk of stroke and systemic embolism in patients with nonvalvular atrial fibrillation. Drugs. 2013;73(8):825-843.

57. Wittkowsky AK. Novel oral anticoagulants and their role in clinical practice. Pharmacotherapy. 2011;31(12):1175-1191.
58. Nutescu EA, Shapiro NL, Ibrahim S, West P. Warfarin and its interactions with foods, herbs and other dietary supplements. Expert Opin Drug Saf. 2006;5(3):433-451.

59. Nutescu E, Chuatrisorn I, Hellenbart E. Drug and dietary interactions of warfarin and novel oral anticoagulants: an update. J Thromb Thrombolysis. 2011;31(3):326-343.

60. Walenga JM, Adiguzel C. Drug and dietary interactions of the new and emerging oral anticoagulants. Int J Clin Pract. 2010;64(7):956-967.

61. APPRAISE Steering Committee and Investigators; Alexander JH, Becker RC, et al. Apixaban, an oral, direct, selective factor Xa inhibitor, in combination with antiplatelet therapy after acute coronary syndrome: results of the Apixaban for Prevention of Acute Ischemic and Safety Events (APPRAISE) trial. Circulation. 2009;119(22):2877-2885.

62. Alexander JH, Lopes RD, James S, et al; APPRAISE-2 Investigators Apixaban with antiplatelet therapy after acute coronary syndrome. N Engl J Med. 2011;365(8):699-708.

\section{Publish your work in this journal}

Drug Design, Development and Therapy is an international, peerreviewed open-access journal that spans the spectrum of drug design and development through to clinical applications. Clinical outcomes, patient safety, and programs for the development and effective, safe, and sustained use of medicines are a feature of the journal, which has also been accepted for indexing on PubMed Central. The manuscript management system is completely online and includes a very quick and fair peer-review system, which is all easy to use. Visit http://www.dovepress.com/testimonials.php to read real quotes from published authors.

Submit your manuscript here: http://www.dovepress.com/drug-design-development-and-therapy-journal 